\title{
Intrapersonal and Interpersonal Sources of Resilience: Mechanisms of the Relationship Between Bullying Victimization and Mental Health Among Migrant Children in China
}

\author{
Kunjie Cui ${ }^{1}$ (D) $\cdot \operatorname{Han} \mathrm{Xie}^{2}$ (D)
}

Accepted: 9 September 2021 /Published online: 18 September 2021

(C) The Author(s) 2021, corrected publication 2021

\begin{abstract}
Compared with their non-migrant peers, migrant children in China face major risks and challenges that may cause them to develop behavioral and psychological problems. Nevertheless, research has seldom addressed their victimization by bullies and its association with their mental health outcomes, much less the roles of intrapersonal and interpersonal sources of resilience in that relationship. In response, this study was designed to examine how bullying victimization both directly and indirectly influences migrant children's mental health through intrapersonal and interpersonal sources of resilience. Data were collected from a school-based multistage random sample of 1,132 migrant children in Grades 4-9 (mean age $=11.88$ years, range $=8-17$ years; boys $=55.6 \%$ ) attending public schools in Nanjing and private schools in Guangzhou, China. Structural equation modeling performed with Amos 25.0 revealed that both intrapersonal and interpersonal sources of resilience mediated the effect of bullying victimization on migrant children's mental health, albeit intrapersonal sources demonstrated a slightly stronger mediation effect. The results thus suggest that social workers and educators should provide effective prevention and intervention strategies that promote intrapersonal and interpersonal sources of resilience among migrant children in China.
\end{abstract}

Keywords Bullying victimization $\cdot$ Mental health $\cdot$ Resilience $\cdot$ Migrant children

Kunjie Cui

cuikunjie@swufe.edu.cn

1 Research Institute of Social Development, Southwestern University of Finance and Economics, No. 555, Liutai Road, Wenjiang District, Chengdu 611130, China

2 School of Public Administration, Central South University, Changsha, China 


\section{Introduction}

With global prevalence, school bullying affects a significant proportion of children and adolescents around the world. In sheer numbers, at least according to the United Nations Educational, Scientific and Cultural Organization (UNESCO, 2017), an estimated 246 million children and adolescents each year experience school bullying in one form or another. In terms of proportions, an opinion poll published in a United Nations International Children's Emergency Fund (UNICEF, 2016) U-Report found that approximately two-thirds of 100,000 young people in 18 countries had been victims of bullying. In China in particular, a national survey of 104,825 students in primary and secondary schools in 29 cities revealed bullying's incidence to be $33.36 \%$, with $4.7 \%$ of the students bullied frequently and $28.66 \%$ bullied occasionally (Yao, 2016). Another study of 501 students in China demonstrated that $53.3 \%$ of students had experienced physical bullying, $61 \%$ verbal insults, and $58.1 \%$ extortion, while $57.1 \%$ had been teased or made fun of (Su et al., 2016). In response to the high prevalence of school bullying, protecting children and adolescents from such aggression has become an important issue in social work and social policy, one related to both public health and human rights.

According to UNESCO (2017), bullying at school is more likely to threaten members of vulnerable groups, particularly ones who are migrants, poor, and/ or of different language and/or cultural backgrounds. Although issues stemming from the bullying victimization of migrants have been extensively examined in Western countries, the bullying of migrant children in China remains underexamined. However, that oversight does not mean that China's migrant child population does not experience bullying at school, as Yao (2016) and Su et al. (2016) have shown, or that the population is not massive and growing. In fact, China's rapid industrialization and urbanization in the past several decades have driven hundreds of millions of migrant workers to leave their rural hometowns for the country's gargantuan cities. With them, their migrant children, by definition no more than 18 years old, have also relocated from rural to urban areas but nevertheless remained unregistered in their new cities of residence under China's household registration system, or hukou. Based on the most recent data, the total number of migrant children in China rose from 19.82 million in 2000 to 34.91 million in 2019 (New Citizen Program, 2021).

For its millions of migrants, China's hukou system poses not only institutional barriers by excluding them from the urban public services system but also social barriers by separating them from other urban residents. For migrant children in particular, such barriers can cause an undue burden of additional risks and challenges. Several studies have shown, for example, that migrant children in urban areas are often devalued, rejected, excluded, and discriminated against, mostly for being marked by low socioeconomic status (SES), minority dialects, unfamiliar customs or behaviors, and an undesirable appearance (Chen et al., 2014; Ye et al., 2016). More recent studies have also shown that migrant children are often perceived as outsiders and more likely to be bullied than their non-migrant peers 
(Cui \& To, 2019, 2020). Because bullying victimization has been documented to be associated with children's mental health problems, such as depression, anxiety and even suicide ideation (Brunstein Klomek et al., 2019; Lee, 2021; Zhang et al., 2019), it is important to explore how it affects migrant children's mental health, whether directly or indirectly.

A potentially significant factor in those associations, resilience has been shown to determine the ways in which individuals behave adaptively under significant stress (Luthar, 1991; Masten, 2001)_for instance, why some children exhibit fewer mental health problems after experiencing bullying victimization. As pioneers in the conceptualization and study of resilience, both Garmezy (1985) and Rutter (2012) have underscored the need for research on the concept to take positive personality dispositions and external social support systems into account. Thus, the resilience framework provides a suitable lens for understanding how internal and external protective factors can predict positive outcomes among individuals exposed to adversity (Egeland et al., 1993). Examining the factors and processes underlying resilience marks an important step toward identifying high-risk individuals as well as toward designing and validating resilience-building interventions (Lee et al., 2013). Because individuals typically confront stress-provoking conditions with various resources and perceptions in order to lessen their impact (Pearlin et al., 1981), the study presented here was designed to investigate how intrapersonal and interpersonal resilience mediate the effects of bullying victimization on the mental health of migrant children in China.

\section{Literature Review}

\section{Bullying Victimization and Mental Health}

Bullying victimization has been documented as a type of stress or traumatic event that can cause mental health problems in children (Arseneault, 2017; Copeland et al., 2013; Isaacs et al., 2008). Victims of continual bullying tend to show problems with internalization-withdrawal, somatic complaints, anxiety, and depression-that are more intense than those of perpetrators and others uninvolved in bullying (Menesini et al., 2009). The influence of victimization can be remarkable and long term. Victims of bullying are at a higher risk of being diagnosed with depression in adulthood than those who have never been victimized, and the association between victimization and depression remains robust when SES and parents' mental illness are considered (Lund et al., 2008). That finding was confirmed by a 40-year longitudinal study showing that frequent bullying victimization during childhood has a long-term impact on mental health outcomes during adulthood and elevates the risk of depression and anxiety (Takizawa et al., 2014).

Although many studies have documented bullying victimization's effect on mental health, the topic warrants exploration from new, alternative perspectives. To start, previous studies have mainly focused on bullying as physical or verbal attacks against victims (Olweus et al., 1999). However, relational bullying should also be examined, along with bullying based on culture, particularly among migrant children from rural 
areas, who may experience social exclusion and acculturation while settling into their urban lives. Furthermore, while traditional bullying plays a key role in predicting negative mental health problems (Dempsey et al., 2009; Hase et al., 2015; Lin et al., 2018), cyberbullying, which has become increasingly serious in China, may also cause mental health problems (Chan \& Wong, 2015, 2017). Thus, in the study presented here, bullying was regarded as a multidimensional concept encompassing physical bullying, verbal bullying, relational bullying, bullying based on culture, and cyberbullying.

Absent from the literature, however, is work addressing the association between bullying victimization and mental health outcomes for rural-to-urban migrant children in China. However, due to the heightened risks faced by migrant children, the individual and contextual resources available to them should be identified, for those resources may help them to adapt to their new urban environments and protect them from the adverse effects of traumatic experiences.

\section{Intrapersonal Sources of Resilience: Positive Personal Attributes}

Resilience embodies the personal qualities that enable individuals to thrive in the face of adversity (Connor \& Davidson, 2003). Typically, resilience has been defined in research studies primarily in terms of intrapersonal functioning (Wright et al., 2005). Components such as personal competence, stress tolerance, acceptance of change, and other positive personal attributes have been linked to how individuals perceive and respond to potential stressors, from extreme events such as exposure to war (Besser et al., 2014) to more common, pervasive events such as bullying victimization (Zhou et al., 2017).

One type of resilience, intrapersonal resilience, has been documented as being associated with better health and well-being, either directly or by mediating the impact of adverse experiences. Intrapersonal resilience can be regarded as a stress-coping ability and key factor in interventions targeting negative mental health outcomes such as depression, anxiety, and other reactions to stress (Anthony, 1987; Connor \& Davidson, 2003; Werner \& Smith, 1982). Empirical research has suggested that higher levels of resilience in terms of mastery, relatedness, and emotional reactivity are related to lower levels of depression (Moore \& Woodcock, 2017). Intrapersonal resilience can also be viewed as a personality process that determines stress appraisal and its emotional outcomes, including the capacity to modulate effect (Block \& Kremen, 1996). For example, Loh et al. (2014) found that intrapersonal resilience mediated the association between characteristic affect and symptoms of depression, with a full mediation effect between positive affect and depression and a partial one between negative affect and depression. In China, Ding et al. (2017) also found that intrapersonal resilience partly mediates the relationship between childhood trauma and depression symptoms.

\section{Interpersonal Sources of Resilience: Social Support}

Along with intrapersonal resilience, interpersonal variables, including social support and other aspects of the social environment, have been thought to play a role in promoting and sustaining resilience despite adversity (Lee et al., 2013; Rutter, 1999). 
Interpersonal sources of resilience such as social support, regarded as an individual's perception of general support or specific supportive behaviors from people in their social network, can enhance personal functioning and protect individuals from adverse outcomes (Tardy, 1985).

As a source of interpersonal resilience, social support has been found to directly affect mental health outcomes (Lakey \& Orehek, 2011; Li et al., 2019). For instance, a national longitudinal study in Australia has indicated that support from friends and family exerts strong direct effects on mental health (Milner et al., 2016). Support from mothers, teachers, and friends has a significant negative effect on depression (Colarossi \& Eccles, 2003), and emotional support from teachers in particular significantly factors into students' social and emotional well-being (Tennant et al., 2015). Likewise, Barrera's (1986) social support deterioration model theorizes that the effect of stressful events or adversities on a person's well-being is mediated by the stressor-induced corrosion of social support. In support, researchers have indeed found that bullying victimization indirectly affects mental health via the mediating effect of peer support (Chen \& Wei, 2013). Thus, both theoretical and empirical findings maintain that social support as an interpersonal source of resilience may contribute to mental health, both directly and by mediating the impact of adverse experiences.

The resilience framework in the study presented here attempts to incorporate not only attributes of children themselves (i.e., intrapersonal sources of resilience) that help them to adapt to adversity but also protective factors in their ecological systems (i.e., interpersonal sources of resilience) that might promote development outcomes. However, what remain unknown are the relative contributions of intrapersonal and interpersonal sources of resilience to healthier outcomes following adverse experiences. In light of growing interest in the mental health of migrant children in China, identifying protective factors for the mental health outcomes of bullied migrant children is valuable. To be precise, determining which variable more strongly promotes mental health outcomes can guide the development of more efficient means of developing resilience and identifying key targets for interventions.

\section{The Present Study}

Despite evidence of the effects of both bullying victimization and resilience on children's mental health, researchers have rarely integrated the two streams when examining how intrapersonal sources of resilience (e.g., positive personal attributes) and interpersonal ones (e.g., perceived social support from parents, peers, and teachers) might mediate the effects of adverse experiences (e.g., bullying victimization) on children's mental health outcomes, whether independently or jointly. Moreover, the integrated resilience framework has never been applied to migrant children, despite their being a highly vulnerable population confronted with residence mobility and assimilation stress. Because children are viewed as the center of ecological systems and their emotional and/or behavioral symptoms as outcomes of their personal traits and interactions with those systems (Bronfenbrenner, 1979), the study aimed to investigate the effects of both intrapersonal and interpersonal sources of resilience 
on mental health among migrant children who experience bullying victimization. It was expected that both sources of resilience would mediate the impact of bullying victimization on mental health. Two hypotheses were thus formulated:

H1: Migrant children who experience more bullying victimization tend to perceive less intrapersonal resilience and are thus likely to report more mental health problems.

$\mathrm{H} 2$ : Migrant children who experience more bullying victimization tend to perceive less interpersonal resilience and are thus likely to report more mental health problems.

\section{Methods}

\section{Participants}

The study's sample included migrant children in Grades 4-9 (Mean age $=11.88$ ) from Nanjing and Guangzhou, China, all recruited via school-based multistage random sampling. In the first stage, two districts in Nanjing and two in Guangzhou where migrants are most concentrated were selected. In the second, a primary school and a secondary school were randomly selected from each district. Third, in each school, approximately 90 students were randomly selected from each grade: Grades 4-6 in primary schools and Grades 7-9 in secondary schools. Following that procedure, the initial sample contained 2,160 children in total.

Participating children received structured questionnaires in their classrooms under the guidance of professionally trained survey monitors. In total, 1,747 children and their parents or guardians signed the consent form and completed the survey, for a response rate of $81 \%$. Among them, 1,165 were migrant children, 473 were non-migrant children, and 109 did not report their migrant status. Expectation maximization which can maximize likelihood functions that arise in statistical estimation (Fessler \& Hero, 1994), was adopted to handle single missing values. A total of 33 cases were excluded due to missing responses related to the primary variables. Thus, 1,132 migrant children were ultimately included in the study.

\section{Measures}

Several measures used in the study were adopted from scales in Western literature. Once the scales were translated and back-translated by professional translators with the help of experts in youth studies, a pilot study was conducted with 100 participants in Grades 4-9 to examine the resulting questionnaire's applicability. After the questionnaire was adjusted and amended in accordance with the data from the pilot study, the measures used in the final version of the questionnaire were as follows.

Bullying victimization was assessed with 15 items taken from the Personal Experiences Checklist (PECK; Hunt et al., 2012), which provides a multidimensional assessment of one's experience with victimization in all types of bullying. The 
PECK, a self-report scale applicable to children at least 8 years old, addresses not only traditional types of bullying-physical (e.g., kicking, shoving, or hitting others), verbal (e.g., calling somebody names, teasing, or making fun of others), and relational (e.g., purposely ignoring or excluding others)—but also cyberbullying (e.g., bullying via text messages, email, and chatrooms) and bullying based on culture (e.g., not interacting with others due to their accents or cultural background). Participants responded to each item on a 5-point Likert scale $(1=$ never, $5=$ every day), with higher scores indicating more experience with bullying victimization (Cronbach's $\alpha=0.90$ ).

Mental health, defined as the psychological state of individuals functioning at a satisfactory level of emotional and behavioral adjustment (Sreevani, 2016), was assessed with the Chinese version of the 12-item General Health Questionnaire (GHQ-12). The GHQ-12 is frequently used across countries and cultures, and the Chinese version of the GHQ has been documented as a reliable, valid self-report instrument for measuring general psychological symptoms among adolescents in China (Li et al., 2009). Andrich and Van Schoubroeck (1989) proposed that the GHQ-12 has two dimensions: positively oriented items and negatively oriented items. Examples of positive items are "Have you recently been feeling reasonably happy all things considered?" and "Have you recently been able to enjoy your normal day-to-day activities?" Examples of negative items are "Have you recently been feeling unhappy and depressed?" and "Have you recently felt constantly under strain?" (Cronbach's $\alpha=0.77)$. Participants replied to the items on a 4-point Likert scale $(1=$ not at all, $4=$ much more than usual), and the total score for the 12 items was computed for each participant. In analysis, the positive items were reservecoded, such that higher scores indicated more mental health problems.

Intrapersonal resilience was assessed with 21 items taken from the Conner-Davidson Resilience Scale (CD-RISC), which has been documented as a valid, reliable measure for assessing resilience (Connor \& Davidson, 2003). Three dimensions-personal competence, stress tolerance, and acceptance of changewere included in the study, based on the results of exploratory and confirmatory factor analyses. Personal competence was measured with seven items, including "I can achieve my goals" and "When things look hopeless, I don't give up." Stress tolerance, meanwhile, was measured with seven items such as "Coping with stress strengthens me" and "Under pressure, I can focus and think clearly." Last, acceptance of change was measured with seven items-for example, "I am able to adapt to change" and "I can deal with whatever comes." Participants responded to the items using a 5-point Likert scale (1=not true at all, 5=true nearly all of the time), with higher scores indicating higher degrees of intrapersonal resilience (Cronbach's $\alpha=0.95)$.

Interpersonal resilience, by contrast, was assessed by 24 items taken from the Child and Adolescent Social Support Scale (Malecki \& Demaray, 2002), which is generally used to measure perceived social support among children and adolescents in Grades 3-12. Three dimensions of social support-parent support, teacher support, and peer support-were included in the study, each measured with eight items such as "My parent(s) help me make decisions," "My parent(s) express pride in me," "My teacher(s) care about me," "My teacher(s) give good advice," "My peers ask me to join activities," 
and "My peers do nice things for me." Participants rated each item on a 5-point Likert scale $(1=$ never, $5=$ always $)$, with higher scores indicating more interpersonal sources of resilience. The Cronbach's alphas for the three scales were 0.85 (parents), 0.90 (teachers), and 0.91 (peers).

Sociodemographic variables controlled in the study were gender $(1=$ boy, $2=$ girl, grade level (i.e., 4-9), type of school ( $1=$ public school, $2=$ private migrant children's school), and family's SES, assessed according to parents' level of education and household income. Whereas both the father's and mother's levels of education were reported as one of seven categories ( $1=$ didn't attend or finish primary school, $7=$ bachelor's degree or higher), family income, in RMB, was assessed by children's self-report of their household's monthly income $(1=0-1,999,6=10,000$ or more $)$.

\section{Data Analysis}

After descriptive statistics and correlations between variables were determined with SPSS 25.0, the hypothesized model was evaluated in structural equation modeling with Amos 25.0. The measurement model, by contrast, was first tested by performing confirmatory factor analysis to ensure that the observed variables represented the corresponding latent variables. Afterward, the structural model was tested to examine the structural paths among key variables. Three indices were adopted to evaluate the models' goodness-of-fit: (a) the likelihood ratio test statistic $\left(\chi^{2}\right)$, in which a non-significant $(p>0.05)$ chi-square value indicates that the hypothetical model fits the sample's data well (Bollen, 1989); (b) the comparative fit index (CFI), in which values exceeding 0.90 indicate an acceptable model fit (Bentler, 1990); and (c) the root mean square error of approximation (RMSEA), in which values less than 0.05 are considered to indicate a close fit (Kline, 2005). Finally, bootstrapping with 2,000 resamples and $95 \%$ bias-corrected confidence intervals was performed to test the mediating effects. A significant indirect effect was assumed if zero was outside the range of the confidence intervals (Preacher \& Hayes, 2008).

\section{Results}

\section{Descriptive Statistics}

Table 1 shows the sample's demographic characteristics. Of the 629 boys and 503 girls with an average age of 11.88 years (range $=8-17$ years), $22.2 \%$ attended a public school and $77.8 \%$ a private migrant children's school. More than $60 \%$ of their parents had graduated from secondary school or less. Table 2 shows the correlations between all of the variables in the study.

\section{Test of the Measurement Model}

The measurement model of the three latent variables (i.e., bullying victimization, intrapersonal resilience, and interpersonal resilience) was tested before the 
Table 1 Descriptive statistics of the participants

\begin{tabular}{|c|c|c|}
\hline & Frequency $(n)$ & Percentage $(\%)$ \\
\hline \multicolumn{3}{|l|}{ Gender } \\
\hline Boy & 629 & 55.6 \\
\hline Girl & 503 & 44.4 \\
\hline \multicolumn{3}{|l|}{ Age Mean $=11.88(\mathrm{SD}=1.84)($ years $)$} \\
\hline \multicolumn{3}{|l|}{ School type } \\
\hline Public school & 251 & 22.2 \\
\hline Private migrant children's school & 881 & 77.8 \\
\hline \multicolumn{3}{|l|}{ Grade } \\
\hline Grade 4 & 227 & 20.1 \\
\hline Grade 5 & 154 & 13.6 \\
\hline Grade 6 & 177 & 15.6 \\
\hline Grade 7 & 238 & 21.0 \\
\hline Grade 8 & 179 & 15.8 \\
\hline Grade 9 & 157 & 13.9 \\
\hline \multicolumn{3}{|l|}{ Father's highest level of education } \\
\hline Didn't attend or finish primary school & 57 & 5.0 \\
\hline Primary school & 163 & 14.4 \\
\hline Secondary school & 465 & 41.1 \\
\hline High school & 169 & 15.0 \\
\hline Technical school & 39 & 3.5 \\
\hline College & 48 & 4.2 \\
\hline Bachelor's degree or higher & 50 & 4.4 \\
\hline Don't know & 126 & 11.1 \\
\hline Missing & 15 & 1.3 \\
\hline \multicolumn{3}{|l|}{ Mother's highest level of education } \\
\hline Didn't attend or finish primary school & 103 & 9.1 \\
\hline Primary school & 215 & 19.0 \\
\hline Secondary school & 414 & 36.6 \\
\hline High school & 127 & 11.2 \\
\hline Technical school & 40 & 3.5 \\
\hline College & 30 & 2.7 \\
\hline Bachelor's degree or higher & 36 & 3.2 \\
\hline Don't know & 143 & 12.6 \\
\hline Missing & 24 & 2.1 \\
\hline \multicolumn{3}{|l|}{ Monthly household income (in RMB) } \\
\hline 0-1999 & 38 & 3.4 \\
\hline 2000-3999 & 200 & 17.7 \\
\hline $4000-5999$ & 250 & 22.1 \\
\hline $6000-7999$ & 175 & 15.4 \\
\hline 8000-9999 & 142 & 12.5 \\
\hline 10,000 or more & 110 & 9.7 \\
\hline Don't know & 201 & 17.8 \\
\hline
\end{tabular}


Table 1 (continued)

\begin{tabular}{ccc}
\hline & Frequency $(n)$ & Percentage $(\%)$ \\
\hline Missing & 16 & 1.4 \\
\hline
\end{tabular}

Table 2 Bivariate correlation of key variables

\begin{tabular}{|c|c|c|c|c|c|c|c|c|}
\hline & 1 & 2 & 3 & 4 & 5 & 6 & 7 & 8 \\
\hline 1. Bullying victimization & 1 & & & & & & & \\
\hline 2. Interpersonal resilience & $-.227 * *$ & 1 & & & & & & \\
\hline 3. Intrapersonal resilience & $-.140 * *$ & $.610 * *$ & 1 & & & & & \\
\hline 4. Mental health & $.329 * *$ & $-.498 * *$ & $-.636^{* * *}$ & 1 & & & & \\
\hline 5. Gender & $-.113 * *$ & $.103 * *$ & -.015 & .033 & 1 & & & \\
\hline 6. Grade & .011 & -.047 & -.037 & $.131 * *$ & -.032 & 1 & & \\
\hline 7. Socioeconomic status & .009 & .035 & $.065^{*}$ & -.021 & .000 & $-.188 * *$ & 1 & \\
\hline 8. School type & .019 & $-.243 * *$ & $-.214 * *$ & $.075^{*}$ & .037 & $-.175^{* *}$ & .032 & 1 \\
\hline
\end{tabular}

\footnotetext{
** Significant at the 0.01 level (2-tailed)

* Significant at the 0.05 level (2-tailed)
}

hypothesized structural model. According to the results, the measurement model fit the data well $\left(\chi^{2}=4,513.186, d f=1,692, p<0.001, \mathrm{CFI}=0.926\right.$, RMSEA $\left.=0.038\right)$, with a CFI greater than 0.90 and an RMSEA less than 0.05 . All observed variables were significantly loaded on the corresponding latent constructs, which suggests that the selected indicators represented the underlying constructs in a statistically reliable manner (factor loading range $=0.57-0.86$ ).

\section{Test of the Structural Model}

A test of the hypothesized structural model also revealed its good fit with the data. The chi-square value was large and significant $\left(\chi^{2}=5,223.668, d f=1,977\right.$, $p<0.001)$, as is commonly observed in large samples. Other goodness-of-fit indices also demonstrated satisfactory results, with a CFI (0.918) exceeding 0.90 and an RMSEA (0.038) less than 0.05 . In total, $52.1 \%$ of the variance in mental health was explained by the model.

Figure 1 presents the standardized solution for the test of the structural model. As shown, bullying victimization exerted a significant direct effect on migrant children's mental health $(\beta=0.22, p<0.001)$. The results of bootstrapping, as hypothesized, indicated that both intrapersonal resilience (95\% CI [0.035, 0.103], $\beta=0.064$, $p=0.001$ ) and interpersonal resilience (95\% CI [0.013, 0.073], $\beta=0.040, p=0.005$ ) mediated bullying victimization's effect on mental health. In particular, migrant children who experienced more bullying victimization tended to perceive less intrapersonal resilience $(\beta=-0.15, p<0.001)$ and were thus likely to report more mental health problems $(\beta=-0.51, p<0.001)$. Migrant children who experienced more bullying victimization also tended to perceive less interpersonal resilience 


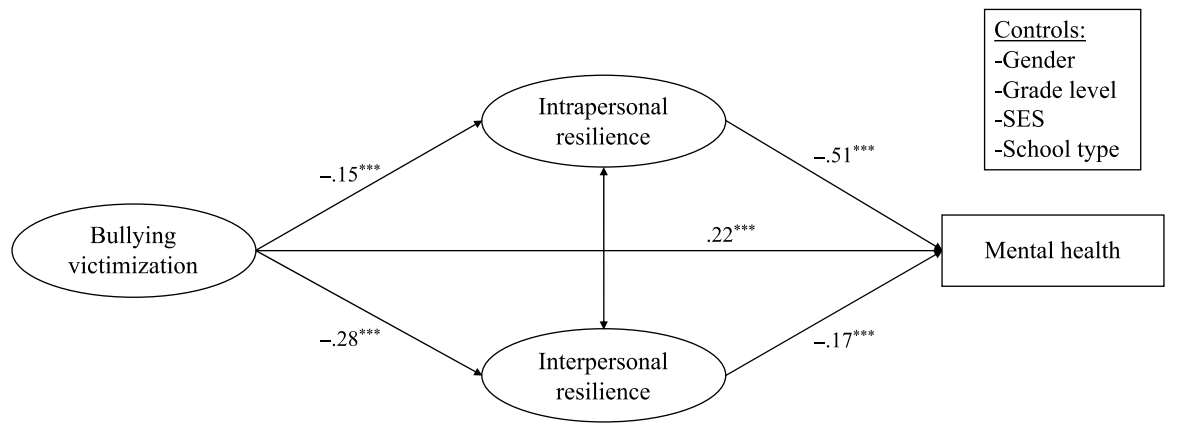

Fig. 1 Standardized solutions for the structural model of direct and mediating effects on mental health among migrant children

$(\beta=-0.28, p<0.001)$ and were thus also likely to report more mental health problems $(\beta=-0.17, p<0.001)$.

\section{Discussion}

With a sample of 1,132 migrant children recruited from two cities on China's eastern coast, the study presented here examined the mediation effects of intrapersonal and interpersonal sources of resilience in the relationship between bullying victimization and children's mental health. It integrated the two steams of understanding of resilience by incorporating both individual (i.e., positive personal attributes) and contextual (i.e., perceived social support) protective factors into a comprehensive model. Its findings furnish evidence supporting the understanding that resilience helps migrant children to adapt when they encounter adverse experiences. In particular, they show that both intrapersonal and interpersonal sources of resilience mediated the effect of bullying victimization on migrant children's mental health.

The results verified the mediating role of intrapersonal sources of resilience between bullying victimization and mental health among migrant children in China, which supports Hypothesis 1. Such evidence means that migrant children who experience bullying tend to report lower levels of intrapersonal resilience and are more likely to manifest mental health problems. Those findings are consistent with empirical results indicating that intrapersonal resilience can mediate the effect of adverse or stressful events on mental health outcomes (Ding et al., 2017; Loh et al., 2014). To date, most studies have examined resilience with study-specific objectives or personal theoretical dispositions; consequently, different dimensions of resilience (e.g., mastery, self-efficacy, and hope) have been addressed. The study presented here involved using the CD-RISC, which was specifically developed to assess resilience in clinical settings, is applicable to cases involving a stressor, and is robust in crosscultural settings (Davydov et al., 2010). Those findings suggest that components of intrapersonal resilience-personal competence, stress tolerance, and acceptance of change-are personal resources that can mediate the effect of bullying victimization 
on mental health. Migrant children in China live in a stressful environment, and empirical studies have shown that migrant children tend to possess lower levels of intrapersonal resilience than non-migrant children (Zhou et al., 2011). The results of the study verify the strong mediation effect of intrapersonal resilience between bullying victimization and mental health among migrant children, which should encourage social workers and educators to develop effective intervention strategies that promote the intrapersonal resilience of migrant children.

The study also revealed the mediating role of interpersonal sources of resilience (e.g., social support) between bullying victimization and mental health among migrant children in China, which supports Hypothesis 2. That finding suggests that migrant children who experience bullying tend to report lower levels of interpersonal resilience and are more likely to manifest mental health problems. Such results support the perspective that the deterioration of social support induced by stressors exerts a mediation effect between stressors and well-being (Barrera, 1986). The results are also consistent with previous empirical evidence that social support plays an important mediating role between bullying victimization and mental health outcomes (Chen \& Wei, 2013; Duru \& Balkis, 2018). As such, the study's findings imply that not only exposure to bullying victimization but also perceptions of intrapersonal and interpersonal resilience, which are reactions to bullying victimization, affect mental health outcomes. Added to that, the study combined parent, teacher, and peer support in the multiple ecological systems of children's social contexts, thereby providing a comprehensive understanding of interpersonal sources of resilience in the analysis of its mediating role.

Bullying victimization also exerted a significant direct effect on migrant children's mental health, which indicates the partial mediation effects of both intrapersonal and interpersonal resilience. Those findings are consistent with empirical results showcasing a negative association between bullying victimization and mental health (Arseneault, 2017; Copeland et al., 2013). At the same time, the findings are also inconsistent with an empirical study that documented bullying victimization's lack of direct effect on mental health despite its indirect effect through social support (Chen \& Wei, 2013). A possible reason for the inconsistency is that, to measure mental health, Chen and Wei (2013) only used positively worded items, not the total score of both positively and negatively worded ones. Addressing the difference, a recent meta-analysis revealed that adopting a composite score of all items is likely to reveal only negligible bias, while calculating subscale scores for positively and negatively worded items separately is not recommended, because they primarily reflect general mental health instead of distinct constructs (Gnambs \& Staufenbiel, 2018). Thus, a composite score of both positively and negatively worded items can provide a more accurate, comprehensive assessment of individual mental health, such that more effective intervention strategies can be provided to protect youth from the psychological damage of bullying victimization.

In sum, the study was built upon an integrated framework incorporating both intrapersonal and interpersonal sources of resilience in order to identify how those factors independently and jointly mediate bullying victimization's impact on the mental health of migrant children in China. The results indicate that both intrapersonal and interpersonal sources of resilience mediate the effect of bullying 
victimization on mental health, although intrapersonal sources had a slightly stronger mediation effect.

\section{Limitations}

In tandem with those findings, several limitations of the study should be noted. First, the causal relationship between variables cannot be unequivocally stated based on cross-sectional data. Because resilience and mental health are established, sustained, and change over time in response to interactions between individual and contextual factors, longitudinal designs are needed to follow individuals at high risk of bullying victimization over an extended period in order to clarify the associations between resilience and responses to adverse experiences. Second, the study exclusively examined the mediating effect of intrapersonal and interpersonal resilience in the association between bullying victimization and mental health outcomes. It is possible, however, that those factors, whether alone or together, moderate stress events and their outcomes. In the future, researchers should test alternative models to achieve a more comprehensive understanding of the roles of intrapersonal and interpersonal sources of resilience. Third, data for the study were collected from two large coastal cities in China, which possibly limits the generalizability of the findings to migrant children across the country. With the increased mobility of China's population, migrant children include individuals who migrate from rural areas to large coastal cities, who move between towns, and who move from small provincial cities to provincial capitals. In that light, future studies should further explore different types of migrant children across China and apply the proposed conceptual framework to different social contexts and social groups.

\section{Implications}

Despite those limitations, the study's findings contribute to advancing theory and, as such, pose important implications for empirical studies and the delivery of social services. Theoretically, the study provides a response to the debate on whether resilience is a personal trait, an outcome of successful adaption, or a dynamic process. That is, resilience can be treated as a process of adaption, during which one's individual traits and interactions with social contexts cooperate to protect them in the face of adversity. The study embraces an integrative view that intrapersonal and interpersonal sources of resilience combine to protect migrant children from bullying victimization's adverse impacts on mental health. The accompanying framework provides a comprehensive understanding of the implications of resilience, which may better bridge theory with practice than current models. The framework can also be applied to other developmental outcomes to further examine its validity and refine theories on resilience. On top of that, resilience closely relates to the positive youth development perspective (Masten, 2014; Qi et al., 2020; Shek, et al., 2019a, b; Sun \& Shek, 2013), and in that light, both of them could be theoretically and practically distinguished and associated in future research. 
Empirically, the study marks an initial effort to examine how intrapersonal and interpersonal sources of resilience jointly and independently mediate the effect of bullying victimization on mental health outcomes among migrant children in China. The effort afforded useful supplements to past research on the separate mediating effects of intrapersonal sources of resilience (Loh et al., 2014) and interpersonal ones (Chen \& Wei, 2013). Bullying victimization, intrapersonal resilience, and interpersonal resilience are all considered to be multidimensional concepts, which helped to more reliably capture the associations between the variables. In addition, the study's findings contribute to emerging literature on the bullying victimization and psychological adjustment of migrant children during rural-to-urban migration experiences, which highlights the need for additional knowledge and resources in support of such a vulnerable population. Because the most recent research consistently shows that multiple protective factors and risk factors relate to the mental health of children in China (e.g., Shek \& Siu, 2019; Zhou et al., 2020a, b, c), future empirical research designed to identify the interactions between those factors and the underlying mechanisms would be helpful.

Practically, the findings imply promising directions for social work practices and services. The significant, strong effects of both intrapersonal and interpersonal sources of resilience suggest that developing resilience-focused interventions for migrant children at risk of bullying victimization could be an efficient strategy for protecting them from mental health problems. Intrapersonal sources of resilience could be improved by experimental learning that enhances children's personal competence, coping skills, and emotional regulation. Activities that help children to set goals, find their strengths, and develop problem-solving skills individually or in groups would enhance both their social and cognitive competence. Children can also be taught to identify and use their personal assets as well as resources in their social environments in order to improve their coping skills and strengthen their stress tolerance. Case work or group work could be organized to give children information on how to deal with negative emotions in constructive ways in order to enhance their positive acceptance of changes. Beyond that, specific intervention programs such as the "Tin Ka Ping P.A.T.H.S. Project," which incorporated 15 constructs of positive youth development, that have consistently proven to be effective in promoting multiple psychosocial competencies and reducing risk behaviors in adolescents could be generalized in schools and communities (Ma et al., 2019; Shek et al., 2019b; Zhu \& Shek, 2020).

Improving interpersonal sources of resilience could also be aided by providing lectures or training programs to enhance support from parents, teachers, and peers. Because parents of migrant children usually have to work long hours and lack the time, ability, and resources to provide children with the support that they need, parent-teacher meetings at schools and/or family education workshops in communities could teach parents how to provide their children with appropriate informational, emotional, instrumental, and appraisal support. Each school should additionally retain a social worker or psychological consultant on staff, and psychological counseling should be provided to children who are struggling and need emotional support. Last, social workers at schools should organize regular group activities as a way to promote teacher-student interactions and cultivate a caring, respectful, 
supportive atmosphere at school. All of those efforts could help children to enhance their resilience and develop better mental health and other developmental outcomes.

Funding This research was supported by the National Social Science Foundation of China (Grant Number: 19ZDA144), and the Humanity and Social Science Youth Foundation of Ministry of Education of China (Grant Number: 17YJC840010).

\section{Declarations}

Conflicts of Interest The authors declared no potential conflicts of interest with respect to the research, authorship, and/or publication of this article.

Ethical Approval The procedures for this study and all consent forms and measurement instruments were approved by the Survey and Behavioral Research Ethics Committee in the Chinese University of Hong Kong, and found to be in compliance with the ethical standards for research involving human subjects.

Open Access This article is licensed under a Creative Commons Attribution 4.0 International License, which permits use, sharing, adaptation, distribution and reproduction in any medium or format, as long as you give appropriate credit to the original author(s) and the source, provide a link to the Creative Commons licence, and indicate if changes were made. The images or other third party material in this article are included in the article's Creative Commons licence, unless indicated otherwise in a credit line to the material. If material is not included in the article's Creative Commons licence and your intended use is not permitted by statutory regulation or exceeds the permitted use, you will need to obtain permission directly from the copyright holder. To view a copy of this licence, visit http://creativecommons.org/licen ses/by/4.0/.

\section{References}

Andrich, D., \& Van Schoubroeck, L. (1989). The General Health Questionnaire: A psychometric analysis using latent trait theory. Psychological Medicine, 19(2), 469-485. https://doi.org/10.1017/S0033 291700012502

Anthony, E. J. (1987). Risk, vulnerability, and resilience: An overview. In E. J. Anthony \& B. J. Cohler (Eds.), The Invulnerable Child (pp. 3-48). Guilford.

Arseneault, L. (2017). The long-term impact of bullying victimization on mental health. World Psychiatry, 16(1), 27. https://doi.org/10.1002/wps.20399

Barrera, M. (1986). Distinctions between social support concepts, measures, and models. American Journal of Community Psychology, 14(4), 413-445. https://doi.org/10.1007/BF00922627

Bentler, P. M. (1990). Comparative fit indexes in structural models. Psychological Bulletin, 107(2), 238246. https://doi.org/10.1037/0033-2909.107.2.238

Besser, A., Weinberg, M., Zeigler-Hill, V., \& Neria, Y. (2014). Acute symptoms of posttraumatic stress and dissociative experiences among female Israeli civilians exposed to war: The roles of intrapersonal and interpersonal sources of resilience. Journal of Clinical Psychology, 70(12), 1227-1239. https://doi.org/10.1002/jclp.22083

Block, J., \& Kremen, A. M. (1996). IQ and ego-resiliency: Conceptual and empirical connections and separateness. Journal of Personality and Social Psychology, 70(2), 349-361. https://doi.org/10. 1037/0022-3514.70.2.349

Brunstein Klomek, A., Barzilay, S., Apter, A., Carli, V., Hoven, C. W., Sarchiapone, M., ... \& Wasserman, D. (2019). Bi-directional longitudinal associations between different types of bullying victimization, suicide ideation/attempts, and depression among a large sample of European adolescents. Journal of Child Psychology and Psychiatry, 60(2), 209-215. https://doi.org/10.1111/jcpp.12951

Bollen, K. A. (1989). A new incremental fit index for general structural equation models. Sociological Methods \& Research, 17(3), 303-316. https://doi.org/10.1177/0049124189017003004 
Bronfenbrenner, U. (1979). The ecology of human development. Harvard University Press.

Chan, H. C. O., \& Wong, D. S. (2015). Traditional school bullying and cyberbullying in Chinese societies: Prevalence and a review of the whole-school intervention approach. Aggression and Violent Behavior, 23, 98-108. https://doi.org/10.1016/j.avb.2015.05.010

Chan, H. C. O., \& Wong, D. S. (2017). Coping with cyberbullying victimization: An exploratory study of Chinese adolescents in Hong Kong. International Journal of Law, Crime and Justice, 50, 71-82. https://doi.org/10.1016/j.ijlcj.2017.04.003

Chen, J. K., \& Wei, H. S. (2013). School violence, social support and psychological health among Taiwanese junior high school students. Child Abuse \& Neglect, 37(4), 252-262. https://doi.org/10. 1016/j.chiabu.2013.01.001

Chen, L., Su, S., Li, X., Tam, C. C., \& Lin, D. (2014). Perceived discrimination, schooling arrangements and psychological adjustments of rural-to-urban migrant children in Beijing, China. Health Psychology and Behavioral Medicine: An Open Access Journal, 2(1), 713-722. https://doi.org/10.1080/ 21642850.2014.919865

Colarossi, L. G., \& Eccles, J. S. (2003). Differential effects of support providers on adolescents' mental health. Social Work Research, 27(1), 19-30. https://doi.org/10.1093/swr/27.1.19

Connor, K. M., \& Davidson, J. R. (2003). Development of a new resilience scale: The Connor-Davidson resilience scale (CD-RISC). Depression and Anxiety, 18(2), 76-82. https://doi.org/10.1002/da. 10113

Copeland, W. E., Wolke, D., Angold, A., \& Costello, E. J. (2013). Adult psychiatric outcomes of bullying and being bullied by peers in childhood and adolescence. JAMA Psychiatry, 70(4), 419-426. https:// doi.org/10.1001/jamapsychiatry.2013.504

Cui, K. J., \& To, S. M. (2019). Migrant status, social support, and bullying perpetration of children in mainland China. Children and Youth Services Review, 107, 104534. https://doi.org/10.1016/j.child youth.2019.104534

Cui, K. J., \& To, S. M. (2020). School climate, bystanders' responses, and bullying perpetration in the context of rural-to-urban migration in China. Deviant Behavior, 1-20. https://doi.org/10.1080/ 01639625.2020 .1752601

Davydov, D. M., Stewart, R., Ritchie, K., \& Chaudieu, I. (2010). Resilience and mental health. Clinical Psychology Review, 30(5), 479-495. https://doi.org/10.1016/j.cpr.2010.03.003

Dempsey, A. G., Sulkowski, M. L., Nichols, R., \& Storch, E. A. (2009). Differences between peer victimization in cyber and physical settings and associated psychosocial adjustment in early adolescence. Psychology in the Schools, 46(10), 962-972. https://doi.org/10.1002/pits.20437

Ding, H., Han, J., Zhang, M., Wang, K., Gong, J., \& Yang, S. (2017). Moderating and mediating effects of resilience between childhood trauma and depressive symptoms in Chinese children. Journal of Affective Disorders, 211, 130-135. https://doi.org/10.1016/j.jad.2016.12.056

Duru, E., \& Balkis, M. (2018). Exposure to bullying at school and mental health of victimized adolescents: The mediation role of social support. Child Abuse \& Neglect, 76, 342-352. https://doi.org/10. 1016/j.chiabu.2017.11.016

Egeland, B., Carlson, E., \& Sroufe, L. A. (1993). Resilience as process. Development and Psychopathology, 5(4), 517-528. https://doi.org/10.1017/S0954579400006131

Fessler, J. A., \& Hero, A. (1994). Space-alternating generalized expectation-maximization algorithm. IEEE Transactions on Signal Processing, 42(10), 2664-2677. https://doi.org/10.1109/78.324732

Garmezy, N. (1985). Stress-resistant children: The search for protective factors. In A. Davids (Ed.), Recent Research in Developmental Psychopathology (pp. 213-233). Pergamon Press.

Gnambs, T., \& Staufenbiel, T. (2018). The structure of the General Health Questionnaire (GHQ-12): Two meta-analytic factor analyses. Health Psychology Review, 12(2), 179-194. https://doi.org/10.1080/ 17437199.2018.1426484

Hase, C. N., Goldberg, S. B., Smith, D., Stuck, A., \& Campain, J. (2015). Impacts of traditional bullying and cyberbullying on the mental health of middle school and high school students. Psychology in the Schools, 52(6), 607-617. https://doi.org/10.1002/pits.21841

Hunt, C., Peters, L., \& Rapee, R. M. (2012). Development of a measure of the experience of being bullied in youth. Psychological Assessment, 24(1), 156-165. https://doi.org/10.1037/a0025178

Isaacs, J., Hodges, E. V., \& Salmivalli, C. (2008). Long-term consequences of victimization by peers: A follow-up from adolescence to young adulthood. International Journal of Developmental Science, 2(4), 387-397. https://doi.org/10.3233/DEV-2008-2404

Kline, R. B. (2005). Principles and practice of structural equation modeling. Guilford Publications. 
Lakey, B., \& Orehek, E. (2011). Relational regulation theory: A new approach to explain the link between perceived social support and mental health. Psychological Review, 118(3), 482-495. https://doi.org/ $10.1037 / \mathrm{a} 0023477$

Lee, J. (2021). Pathways from childhood bullying victimization to young adult depressive and anxiety symptoms. Child Psychiatry \& Human Development, 52(1), 129-140. https://doi.org/10.1007/ s10578-020-00997-4

Lee, J. E., Sudom, K. A., \& Zamorski, M. A. (2013). Longitudinal analysis of psychological resilience and mental health in Canadian military personnel returning from overseas deployment. Journal of Occupational Health Psychology, 18(3), 327-337. https://doi.org/10.1037/a0033059

Li, C., Wu, Q., \& Liang, Z. (2019). Effect of poverty on mental health of children in rural China: The mediating role of social capital. Applied Research in Quality of Life, 14(1), 131-153. https://doi.org/ 10.1007/s11482-017-9584-X

Li, W. H., Chung, J. O., Chui, M. M., \& Chan, P. S. (2009). Factorial structure of the Chinese version of the 12-item General Health Questionnaire in adolescents. Journal of Clinical Nursing, 18(23), 3253-3261. https://doi.org/10.1111/j.1365-2702.2009.02905.x

Lin, P. C., Yen, C. N., Lin, H. C., Wang, P. W., Liu, T. L., Hu, H. F., \& Yen, C. F. (2018). Relationships between involvement in school bullying and quality of life in Taiwanese adolescents. Applied Research in Quality of Life, 13(3), 545-559. https://doi.org/10.1007/s11482-017-9544-5

Loh, J. M., Schutte, N. S., \& Thorsteinsson, E. B. (2014). Be happy: The role of resilience between characteristic affect and symptoms of depression. Journal of Happiness Studies, 15(5), 1125-1138. https://doi.org/10.1007/s10902-013-9467-2

Lund, R., Nielsen, K. K., Hansen, D. H., Kriegbaum, M., Molbo, D., Due, P., \& Christensen, U. (2008). Exposure to bullying at school and depression in adulthood: A study of Danish men born in 1953. The European Journal of Public Health, 19(1), 111-116. https://doi.org/10.1093/eurpub/ckn101

Luthar, S. S. (1991). Vulnerability and resilience: A study of high-risk adolescents. Child Development, 62(3), 600-616. https://doi.org/10.1111/j.1467-8624.1991.tb01555.x

Ma, C. M. S., Shek, D. T. L., \& Chen, J. M. T. (2019). Changes in the participants in a communitybased positive youth development program in Hong Kong: Objective outcome evaluation using a one-group pretest-posttest design. Applied Research in Quality of Life, 14(4), 961-979. https://doi. org/10.1007/s11482-018-9632-1

Malecki, C. K., \& Demaray, M. K. (2002). Measuring perceived social support: Development of the child and adolescent social support scale (CASSS). Psychology in the Schools, 39(1), 1-18. https://doi. org/10.1002/pits. 10004

Masten, A. S. (2001). Ordinary magic: Resilience processes in development. American Psychologist, 56(3), 227-238. https://doi.org/10.1037//0003-066x.56.3.227

Masten, A. S. (2014). Invited commentary: Resilience and positive youth development frameworks in developmental science. Journal of Youth and Adolescence, 43, 1018-1024. https://doi.org/10.1007/ s10964-014-0118-7

Menesini, E., Modena, M., \& Tani, F. (2009). Bullying and victimization in adolescence: Concurrent and stable roles and psychological health symptoms. The Journal of Genetic Psychology, 170(2), 115-134. https://doi.org/10.3200/GNTP.170.2.115-134

Milner, A., Krnjacki, L., Butterworth, P., \& LaMontagne, A. D. (2016). The role of social support in protecting mental health when employed and unemployed: A longitudinal fixed-effects analysis using 12 annual waves of the HILDA cohort. Social Science \& Medicine, 153, 20-26. https://doi.org/10. 1016/j.socscimed.2016.01.050

Moore, B., \& Woodcock, S. (2017). Resilience, bullying, and mental health: Factors associated with improved outcomes. Psychology in the Schools, 54(7), 689-702. https://doi.org/10.1002/pits.22028

New Citizen Program (2021). The review of education for children of migrant population in China in 2020. Retrieved 16 March 2021, from https://weibo.com/ttarticle/p/show?id=230940461896028 4025088\#_loginLayer_1626532587305

Olweus, D., Limber, S., \& Mihalic, S. F. (1999). Blueprints for violence prevention, book nine: Bullying prevention program. Boulder, CO: Center for the Study and Prevention of Violence, 12(6), 256-273.

Pearlin, L. I., Menaghan, E. G., Lieberman, M. A., \& Mullan, J. T. (1981). The stress process. Journal of Health and Social Behavior, 22(4), 337-356. https://doi.org/10.2307/2136676

Preacher, K. J., \& Hayes, A. F. (2008). Asymptotic and resampling strategies for assessing and comparing indirect effects in multiple mediator models. Behavior Research Methods, 40(3), 879-891. https:// doi.org/10.3758/BRM.40.3.879 
Qi, S., Hua, F., Zhou, Z., \& Shek, D. T. (2020). Trends of positive youth development publications (1995-2020): A scientometric review. Applied Research in Quality of Life, 1-26. https://doi.org/ 10.1007/s11482-020-09878-3

Rutter, M. (1999). Resilience concepts and findings: Implications for family therapy. Journal of Family Therapy, 21(2), 119-144. https://doi.org/10.1111/1467-6427.00108

Rutter, M. (2012). Resilience as a dynamic concept. Development and Psychopathology, 24(2), 335344. https://doi.org/10.1017/S0954579412000028

Shek, D. T., Dou, D., Zhu, X., \& Chai, W. (2019a). Positive youth development: Current perspectives. Adolescent Health, Medicine and Therapeutics, 10, 131-141. https://doi.org/10.2147/AHMT. S179946

Shek, D. T., \& Siu, A. M. (2019). "UNHAPPY" environment for adolescent development in Hong Kong. Journal of Adolescent Health, 64(6), S1-S4. https://doi.org/10.1016/j.jadohealth.2019.01. 007

Shek, D. T. L., Zhu, X., Leung, J. T. Y., Lee, T. Y., \& Wu, F. K. Y. (2019b). Evaluation of the Project P.A.T.H.S. in mainland China: Findings based on student diaries. Research on Social Work Practice, 29(4), 410-419. https://doi.org/10.1177/1049731517745994.

Sreevani, R. (2016). A guide to mental health and psychiatric nursing. Jaypee Brothers Publishers.

Su, J. C., Xu, S. H., \& Yang, H. M. (2016). An analysis of the causes and countermeasures of school bullying in primary and middle schools from the perspective of family education. Journal of the Chinese Society of Education, (11), 18-23. http://www.jcse.com.cn/CN/Y2016/V0/I11/18

Sun, R. C., \& Shek, D. T. (2013). Longitudinal influences of positive youth development and life satisfaction on problem behaviour among adolescents in Hong Kong. Social Indicators Research, 114(3), 1171-1197. https://doi.org/10.1007/s11205-012-0196-4

Takizawa, R., Maughan, B., \& Arseneault, L. (2014). Adult health outcomes of childhood bullying victimization: Evidence from a five-decade longitudinal British birth cohort. American Journal of Psychiatry, 171(7), 777-784. https://doi.org/10.1176/appi.ajp.2014.13101401

Tardy, C. H. (1985). Social support measurement. American Journal of Community Psychology, 13(2), 187-202. https://doi.org/10.1007/BF00905728

Tennant, J. E., Demaray, M. K., Malecki, C. K., Terry, M. N., Clary, M., \& Elzinga, N. (2015). Students' ratings of teacher support and academic and social-emotional well-being. School Psychology Quarterly, 30(4), 494-512. https://doi.org/10.1037/spq0000106

UNESCO, United Nations Educational, Scientific and Cultural Organization (2017). School Violence and Bullying: Global Status Report. UNESCO.

UNICEF, United Nations International Children's Emergency Fund (2016). Two-thirds of young people in more than 18 countries say they have been victims of bullying. Retrieved 1 August 2020, from https://www.unicef.org/press-releases/two-thirds-young-people-more-18-countries-saythey-have-been-victims-bullying

Werner, E. E., \& Smith, R. S. (1982). Vulnerable but invincible: A longitudinal study of resilient children and youth. McGraw Hill.

Wright, M. O. D., Fopma-Loy, J., \& Fischer, S. (2005). Multidimensional assessment of resilience in mothers who are child sexual abuse survivors. Child Abuse \& Neglect, 29(10), 1173-1193. https://doi.org/10.1016/j.chiabu.2005.04.004

Yao, J. L. (2016). Relying solely on punishment can't prevent the occurrence of school bullying. People's Daily. Retrieved 20 June 2020, from http://opinion.people.com.cn/n1/2016/0614/c100328441629.html

Ye, Z., Chen, L., Harrison, S. E., Guo, H., Li, X., \& Lin, D. (2016). Peer victimization and depressive symptoms among rural-to-urban migrant children in China: The protective role of resilience. Frontiers in Psychology, 7, 1542. https://doi.org/10.3389/fpsyg.2016.01542

Zhang, H., Chi, P., Long, H., \& Ren, X. (2019). Bullying victimization and depression among leftbehind children in rural China: Roles of self-compassion and hope. Child Abuse \& Neglect, 96, 104072. https://doi.org/10.1016/j.chiabu.2019.104072

Zhou, Q., Guo, S., \& Lu, H. J. (2020a). Well-being and health of children in rural China: The roles of parental absence, economic status, and neighborhood environment. Applied Research in Quality of Life, 1-15. https://doi.org/10.1007/s11482-020-09859-6

Zhou, W. J., Gao, W. B., Sun, X. Y., \& Luo, J. (2011). Psychological resilience features of urban migrant children and rural left-behind children in Sichuan province of China. Journal of Peking University. Health Sciences, 43(3), 386-390. https://doi.org/10.3969/j.issn.1671-167X.2011.03. 015 
Zhou, Z. K., Liu, Q. Q., Niu, G. F., Sun, X. J., \& Fan, C. Y. (2017). Bullying victimization and depression in Chinese children: A moderated mediation model of resilience and mindfulness. Personality and Individual Differences, 104, 137-142. https://doi.org/10.1016/j.paid.2016.07.040

Zhou, Z., Shek, D. T., \& Zhu, X. (2020b). The importance of positive youth development attributes to life satisfaction and hopelessness in mainland Chinese adolescents. Frontiers in Psychology, 11, 2599. https://doi.org/10.3389/fpsyg.2020.553313

Zhou, Z., Shek, D. T., Zhu, X., \& Dou, D. (2020c). Positive youth development and adolescent depression: A longitudinal study based on mainland Chinese high school students. International Journal of Environmental Research and Public Health, 17(12), 4457. https://doi.org/10.3390/ijerph17124457

Zhu, X., \& Shek, D. T. L. (2020). Impact of a positive youth development program on junior high school students in mainland China: A pioneer study. Children and Youth Services Review, 114, 105022. https://doi.org/10.1016/j.childyouth.2020.105022

Publisher's Note Springer Nature remains neutral with regard to jurisdictional claims in published maps and institutional affiliations. 